\title{
Varicela, difteria e febre maculosa brasileira: aspectos epidemiológicos no Estado de São Paulo*
}

\author{
Chickenpox, diphthteria and Brazilian rickettsial disease: epidemiology of the \\ state of São Paulo
}

\section{VARICELA}

A varicela é uma doença que sofreu profunda mudança de imagem. Considerada anos atrás uma doença benigna da infância, incômodo pelo qual todas as crianças deveriam passar mais cedo ou mais tarde, hoje ela é vista como de fato é, um sério problema que se agrava com o passar do tempo.

A notificação da doença não é compulsória em casos isolados, porém os surtos decorrentes deste agravo em creches, préescolas, escolas, comunidade em geral, devem ser notificados no Sistema de Informação de Agravos Notificáveis (SINAN). Por esse motivo, os casos notificados não refletem a realidade.

Nos EUA, antes do uso ampliado da vacina, a cada ano o número estimado de casos de varicela era de aproximadamente quatro milhões, equivalente a uma coorte anual de nascidos. Mantida a mesma proporção, teríamos, no Estado de São Paulo por volta de 650 mil casos anuais. A tabela abaixo demonstra a situação dos óbitos decorrentes da varicela no Estado de São Paulo.

Ainda que apresente uma letalidade relativamente baixa em crianças normais (cerca de dois óbitos para cada $100 \mathrm{mil}$ casos), pode ser muito grave em determinados grupos etários, como em recém-nascidos, em que a letalidade chega a 30\%. Em crianças com comprometimento da imunidade a letalidade é de sete a $20 \%$. A necessidade de hospitalização, no entanto, chega a uma para cada 600 casos.

Crianças institucionalizadas ou que ficam em creches costumam ter quadros mais graves, com maior letalidade. Nestas situações, assim como em domicílios unifamiliares, a taxa de ataque secundário é de $90 \%$.

A par de uma letalidade elevada em determinados grupos, a varicela apresenta o risco de infecção secundária grave pelo Streptococcus pyogenes (o estreptococo beta-hemolítico do grupo A), que muitas vezes evolui para a síndrome do cho- que tóxico ou para um quadro necrotizante grave que, se não fatal, é mutilante. Outra causas de óbito são as encefalite e pneumonia virais.

A vacina contra a varicela é uma vacina de vírus vivo atenuado, da qual existem três apresentações comerciais no Brasil (Varicela Biken $®$, Varilrix ${ }^{\circledR}$ e Varivax ${ }^{\circledR}$ ), todas elas, no entanto, utilizando a cepa japonesa original, Oka.

A eficácia da vacina da varicela é elevada, sendo próxima de $100 \%$ para formas graves e de $94 \%$ a $98 \%$ após uma única dose. A vacinação é recomendada para crianças a partir de um ano de idade. A vacinação de lactentes não é recomendada, não havendo estudos que autorizem seu uso. A vacina da varicela pode ser utilizada simultaneamente com qualquer outra vacina, inclusive as de vírus vivo (como a de sarampo, caxumba e rubéola). A comercialização da vacina combinada contra a varicela, o sarampo, a rubéola e a caxumba é esperada para breve.

A imunização contra a varicela não faz parte do Programa Nacional de Imunizações, porém a vacina está disponível nos Centros de Imunobiológicos Especiais para uso nas seguintes situações:

- pessoas suscetíveis à varicela que serão submetidos a transplantes de órgãos sólidos, pelo menos três semanas antes do ato cirúrgico;

- $\quad$ profissionais de saúde, pessoas e familiares de suscetíveis a varicela e imunocompetentes, que estejam em convívio domiciliar ou hospitalar com pacientes imunocomprometidos;

- pacientes infectados pelo HIV, assintomático ou oligossintomático, sem alteração dos linfocitos CD4;

- pessoas suscetíveis a doença e imunocompetentes, no momento da internação em enfermaria onde haja caso de varicela;

- bloqueio em enfermarias hospitalares;

- população indígena. 
Tabela - Distribuição do número de óbitos decorrentes da varicela. Estado de São Paulo, 1996 a 2003.

\begin{tabular}{lcccccccc}
\hline Ano & 1996 & 1997 & 1998 & 1999 & 2000 & 2001 & 2002 \\
\hline Óbitos & 47 & 39 & 30 & 67 & 24 & 29 & 30 \\
\hline
\end{tabular}

Fonte: SEADE - Fundação Sistema Estadual de Análise de Dados. CVE - Centro de Vigilância Epidemiológica da Secretaria de Estado da Saúde

Surtos de varicela ocorrem de maneira cíclica, a cada quatro anos, aproximadamente.

Dados da Secretaria de Higiene e Saúde do Município de São Paulo indicam que crianças que freqüentam creches apresentam um maior risco de óbito. Esse achado é compatível com a literatura internacional.

Em 2003, com a ocorrência de um surto e levando em conta a informação acima e o fato de que aos cinco anos mais de $50 \%$ da população infantil de São Paulo já apresenta anticorpos protetores, a Secretaria Estadual da Saúde resolveu ampliar as indicações da vacinação incluindo - crianças suscetíveis (ausência de história da doença) a varicela, que freqüentam creches em período integral (manhã e tarde), onde haja caso(s) de varicela. Serão vacinadas as crianças na faixa etária de 1 a 5 anos de idade (5 anos, 11 meses e 29 dias).

Foram aplicadas, até 10 de outubro de 2003, 42.082 doses da vacina. Infelizmente, a pequena disponibilidade de vacinas no mercado impediu uma cobertura vacinal maior.
Vários estudos disponíveis na literatura mostram que a história referida pela mãe é suficiente para saber se uma criança maior ou adolescente teve varicela. Na condição de ausência de história de adoecimento, recomenda-se a vacinação em qualquer idade, particularmente profissionais de saúde. Mulheres que pretendem engravidar e que não recordam ter tido varicela devem ser vacinadas, uma vez que a varicela congênita ou neonatal é uma forma grave da doença, inclusive com malformações fetais. Em adolescentes ( $>13$ anos) $\mathrm{e}$ adultos o número recomendado de doses pode ser de duas, conforme a apresentação comercial.

A tolerância à vacina é muito boa, com cerca de $10 \%$ das crianças apresentando alguma reação local, e cerca de 4\% apresentando um discreto exantema máculo-papular (média de duas a cinco lesões), eventualmente podendo haver febre.

$\mathrm{O}$ risco de transmissão secundária é praticamente inexistente, e a vacinação é protetora mesmo após a exposição, desde que feita até 72 horas.

\section{DIFTERIA}

A difteria é uma doença infecciosa aguda, imunoprevinível e de notificação compulsória, caracterizada pela presença de uma pseudomembrana localizada principalmente em árvore respiratória, que pode produzir sintomatologia sistêmica pela ação de uma exotoxina. É causada pelo Corynebacterium diphtheriae, um bacilo Gram positivo, com quatro biotipos: gravis, mitis, intermedius e belfanti. Apesar dos nomes, não há correlação entre os biotipos e a virulência dos bacilos.

A mais remota descrição sobre sua ocorrência vem de Arataeus, o Capadócio (181-138 a.C.), sob o título Úlceras sobre amígdalas. Antes do advento da vacina, reconhecia-se a difteria como a maior causa de morbidade entre as crianças em muitos países industrializados, com letalidade variando de $5 \%$ a $10 \%$ dos casos.

Desde 1980, a incidência da doença vem apresentando declínio. Em 1990, foram confirmados 640 casos e em 2001, apenas 19 . A letalidade varia de $5 \%$ a $10 \%$, pode, em alguns anos, atingir 20\%. Em 2001 a letalidade foi de 8,4\%. No Estado de São Paulo já se observa nítido deslocamento para faixas etárias maiores de 15 anos, condição também observada em vários outros países na era considerada pós-vacinal.

Entre outros fatores, a introdução da vacinação em larga

escala com o toxóide diftérico, após as décadas de 1940 e 1950, teve grande impacto na sua incidência, chegando-se até à eliminação virtual em alguns desses países. Entretanto, na década de 1990, a ocorrência de uma epidemia de grandes proporções que atingiu a população dos novos países independentes da extinta União Soviética e outros da Europa Ocidental, colocou a difteria entre as doenças re-emergentes, com grandes desafios pela frente.

No Brasil, o controle da difteria deu-se, principalmente, na década de 1990, apesar do Programa Nacional de Imunização ter sido implantado no início dos anos 1970.

O ser humano constitui-se no único reservatório, como doente ou portador, e sua transmissão se dá por meio de gotículas de secreção respiratória (espirro, tosse ou fala). Mais raramente, por fômites, alimentos e objetos contaminados. Sem tratamento, a transmissibilidade varia de duas a quatro semanas. O período de incubação é de um a seis dias, podendo atingir até 10 dias. A difteria pode afetar todas as pessoas suscetíveis, de qualquer idade e sexo.

O quadro inicia-se com sintomas inespecíficos, como febre baixa, anorexia e mal-estar. Em seguida, ocorre formação das pseudomembranas aderentes, que se caracterizam por coloração branco-acinzentada com um halo de palidez ao 
seu redor, e um aspecto consistente e homogêneo. O odor fétido é característico, relacionado à necrose. A doença típica manifesta-se por comprometimento acentuado do estado geral do paciente, que se mostra prostrado e pálido (toxemia). A queixa de dor de garganta pode ser discreta, independentemente da localização ou quantidade de placas existentes.

O estabelecimento de complicações pode estar relacionado com: localização e extensão da membrana e/ou quantidade de toxina absorvida e/ou estado imunitário do paciente.

Em geral, as complicações aparecem durante a segunda semana de evolução da doença; mais raramente, são observadas desde o início ou mais tardiamente, alguns meses depois.

Sendo uma doença que exige medidas de controle imediatas junto aos comunicantes, em casos suspeitos a notificação à vigilância epidemiológica deve ser feita com urgência, por telefone ou fax, por exemplo. A investigação procederá ao preenchimento da ficha epidemiológica de difteria, com notificação do caso no Sistema de Informação Nacional de Agravos de Notificação; confirmação laboratorial ou clínica dos casos; identificação dos comunicantes íntimos; investigação da situação vacinal destes comunicantes e vacinação seletiva imediata; pesquisa de casos secundários através do exame clínico e vigilância sanitária (sete dias) de todos os comunicantes; pesquisa do estado de portador nos comunicantes íntimos.

O paciente deve ficar em isolamento respiratório (precauções por gotículas) por 14 dias e até que sejam obtidas duas culturas negativas, com intervalo de 24 horas entre elas, após a interrupção do antibiótico.

A notificação precoce e a investigação epidemiológica têm a finalidade de determinar a magnitude do problema, identificar a área geográfica de ocorrência e os grupos populacionais mais atingidos, além de avaliar a suscetibilidade da população da área envolvida e desencadear as medidas de con-

\section{FEBRE MACULOSA BRASILEIRA}

A Febre Maculosa Brasileira (FMB) é uma doença infecciosa, febril, aguda, transmitida por carrapatos, de elevada letalidade. Devido ao número crescente de casos diagnosticados Brasil e da expansão das chamadas áreas de transmissão, vem sendo considerada um paradigma de doença emergente. Entretanto, ao considerar que já em 1929 Piza descreve o Typho Exanthematico Paulista, cujas características clínicas, anatomopatológicas e epidemiológicas se assemelham à atual FMB e corresponderiam a um mesmo agravo, na verdade trata-se da re-emergência da doença no Estado de São Paulo, assim como já ocorreu em Minas Gerais.

Em São Paulo, está em andamento um programa de vigilância acarológica, cujo objetivo é melhor conhecer essa fauna no Estado, sobretudo em áreas de transmissão de FMB. Em 1929, houve relatos de casos, provavelmente os primeiros trole pertinentes, para interromper a cadeia de transmissão, evitando surtos ou epidemias.

O tratamento específico para a difteria é o soro antidiftérico. De origem heteróloga, sua administração pode trazer complicações graves, tais como o choque anafilático e a doença do soro. Desse modo, recomenda-se o encaminhamento do suspeito a hospitais de referência, verificando se o paciente apresentou, anteriormente, quadros de hipersensibilidade; se já fez uso de imunoglobulinas de origem eqüina; mantém contato freqüente com animais (principalmente eqüinos).

A difteria não é mais somente uma "doença própria da infância” e ocorre mesmo em pessoas completamente e recentemente vacinadas. As lesões que fazem o diagnóstico diferencial devem ser observadas juntamente com o quadro geral do paciente.

É uma doença potencialmente grave e necessita de assistência médico-hospitalar imediata. Os casos suspeitos devem ser encaminhados para hospitais de referência que dispõem de um estoque de soro antidiftérico e contam com pessoas treinadas no manuseio desses pacientes.

Na suspeita de um quadro de difteria, é imperiosa a realização do eletrocardiograma tanto na internação como no acompanhamento desse paciente.

O bom prognóstico da difteria está diretamente relacionado ao estado imunitário do paciente, à precocidade da instituição do soro antidiftérico, à ausência de "pescoço taurino", à ausência de manifestações hemorrágicas, à não invasibilidade das placas e à ausência de miocardite precoce ou de insuficiência renal.

A doença normalmente não confere imunidade permanente. O convalescente deve ser vacinado após a alta hospitalar.

descritos no Brasil, todos ocorridos na região da Grande São Paulo, de onde, até a década de 1980, os casos descritos eram provenientes.

A partir de 1987, quando foi confirmado laboratorialmente o primeiro caso de FMB em Pedreira, Interior paulista, vários casos foram registrados nas regiões de Campinas e São João da Boa Vista, então a principal área de transmissão no Estado. Mais recentemente, entretanto, a doença vem ocorrendo em regiões até então não consideradas de risco para transmissão. Percebe-se, ainda, que não mais se restringe a áreas rurais e de mata, mas também as peri-urbanas e urbanas, inclusive parques públicos. De notificação compulsória desde 2001, no Brasil, e 2002, no Estado de São Paulo, onde, até maio passado, foram confirmados 78 casos de FMB, dos quais 31 óbitos. 
A FMB é causada pela Rickettsia rickettsii, família Rickettsiaceae, bactéria Gram-negativa de vida intracelular obrigatória. Em humanos infecta primariamente células endoteliais de vasos de pequeno e médio calibres do hospedeiro, levando a um quadro de vasculite dissiminada.

No Brasil, o carrapato Amblyomma cajennense - "carrapato estrela"(adultos), "vermelinhos" (ninfas), "micuim" (larva) é o principal vetor da FMB, mas outras espécies de Amblyomma também podem transmití-la. Além dos próprios carrapatos vetores, que têm complexo ciclo biológico, são potenciais reservatórios: animais silvestres (capivara), e domésticos (cães e eqüinos). Humanos não são reservatórios e não participam do ciclo do agente, sendo hospedeiros acidentais.

Acredita-se que as larvas e ninfas apresentem maior potencial de infectar os humanos e seu parasitismo é comumente despercebido. A distribuição sazonal da doença sugere correlação com as formas de ninfa e adulta do carrapato, entre julho e novembro, que abrigam provavelmente a maior carga parasitária e, assim, são vetores mais eficientes.

A transmissão da riquétsia não se dá antes de 4 a 6 horas de parasitismo do carrapato. Pode ocorrer transmissão através de escoriações na pele, após destruição de carrapato quando da sua retirada; e a parenteral acidental por agulhas e outros instrumentos contaminados não pode ser descartada. A suscetibilidade é universal, sendo a imunidade possivelmente duradoura. A incubação é 2 a 14 dias (usualmente 7). O período de incubação parece ser inversamente proporcional ao volume do inóculo.

As manifestações clínicas apresentam um espectro de gravidade que vai desde casos oligossintomáticos até os extremamente graves, com taxas de letalidade entre $40 \%$ a $70 \%$. Inquéritos soroepidemiológiocos em áreas de transmissão sugerem que formas assintomáticas podem ocorrer. Nos municípios de Pedreira (SP) e Novo Cruzeiro (MG) foram encontrados, respectivamente, $5,3 \%$ e $4,11 \%$ de soropositividade para riquétsias do grupo da febre maculosa indivíduos sadios. Tais achados não significam, necessariamente, quadros assintomáticos de FMB. Podem ser infecções riquétsias não patogênicas do mesmo grupo.

A febre, presente em quase $100 \%$ dos indivíduos, é manifestação inicial geralmente associada a outros sintomas inespecíficos, cefaléia, mialgia, dor abdominal, náusea e vômitos. O exantema, característica principal da doença, ocorre geralmente entre o $3^{\circ}$ e $5^{\circ}$ dias após o início dos sintomas. Inicialmente maculo-papular, acomete punhos e tornozelos progredindo para outras regiões e se tornando petequial. Nos casos graves, a confluência das lesões leva a sufusões hemorrágicas, necrose e gangrena, podendo ocorrer insuficiências renal e respiratória, meningoencefalite que pode evo- luir para coma, hepatite e manifestações hemorrágicas diversas (epistaxe, gengivorragia, hematúria, enterorragia, hemoptise), hipotensão e choque.

O diagnóstico específico da doença pode ser realizado por testes imunológicos, microbiológicos, imunohistoquímicos e de biologia molecular. A sorologia detecta anticorpos específicos anti-Rickettsia do grupo da febre maculosa por técnica de imunofluorescência indireta(IFI). $\mathrm{O}$ isolamento de riquétsias pode ser feito por cultura de coágulo e fragmentos de pele.

A imunohistoquímica com anticorpos específicos antiRickettsia rickettsii pode ser realizada com fragmentos de pele e vísceras. A reação de PCR, mas não disponível na rotina, pode vir a exercer importante papel tanto na prática clínica como no estudo do agente etiológico e na melhor compreensão das características epidemiológicas da doença.

Nas fases iniciais, devem ser considerados diagnósticos diferenciais da FMB, entre outros: sarampo, rubéola, dengue clássico, mononucleose infecciosa, sífilis secundária, enteroviroses, borreliose de Lyme, e reações de hiperssensibilidade. Nos quadros mais graves, em que são comuns icterícia e manifestações hemorrágicas: leptospirose, doença meningocócica, febre hemorrágica e síndrome do choque da dengue, febre amarela, febre tifóide, sepse, malária grave por Plasmodium falciparum, febre purpúrica brasileira, arboviroses, outras riquetsioses, púrpuras trombocitopênicas imunes, hepatites virais e, em alguns casos, hantavírus.

Na suspeita de FMB, recomenda-se a introdução imediata da antibioticoterapia com espectro de ação contra riquétsias. A doxiciclina é a droga de escolha, mas é contra-indicada a crianças e gestantes. O cloranfenicol é droga alternativa quando não é possível usar a doxiciclina. Quando necessário, adotar medidas de suporte ventilatório, hemodiálise e transfusão de hemoderivados, entre outra, gerais, para manter a estabilidade hemodinâmica do paciente.

Não há vacina disponível e a antibioticoterapia profilática não é recomendada. A melhor medida, portanto, é evitar a exposição ao carrapato, em área de transmissão ou não $\mathrm{O}$ auto-exame deve ser feito pelo menos a cada 4 horas. A retirada do carrapato deve ser cuidadosa, evitando o seu esmagamento. Casos suspeitos caracterizam-se por febre de início recente, mialgia, cefaléia e história de exposição a carrapatos. A confirmação se faz pela sorologia (IFI) positiva para riquétsias do grupo da febre maculoas ou isolamento de riquétsias em cultura ou exame imunohistoquímico.

Diante da confirmação, ações que visem identificar e investigar o local provável de infecção devem ser desencadeadas e, posteriormente, adotadas medidas de controle ambiental, educativas e de prevenção. 